\title{
COVID-19 and Dentistry: Analysis of available information on a virtual platform. A descriptive and observational study
}

\author{
Natan Mecler, ${ }^{1}$ Thiago Senna, ${ }^{1}$ Beatriz Tholt, ${ }^{2}$ Josué Lima-Junior, ${ }^{1}$ Dennis de Carvalho Ferreira ${ }^{1,2}$ \\ ${ }^{1}$ School of Dentistry, Estácio de Sá University, Rio de Janeiro, RJ, Brazil. \\ ${ }^{2}$ School of Dentistry, Veiga de Almeida University, Rio de Janeiro, RJ, Brazil. \\ - Conflicts of interest: none declared.
}

\section{Abstract}

Objective:to evaluate the information available on the Google ${ }^{\circledR}$ search site concerning the relationship between dentistry and infection with the new coronavirus, and its concurrence with the current literature. Material and Methods: a descriptive and observational study was conducted by a private university in Rio de Janeiro, Brazil, to analyze the Google ${ }^{\circledR}$ search platform and the sites found through a previously prepared questionnaire. Results: the expressions "Coronavirus and dentistry", "Oral health and Coronavirus" and "Tooth fracture and Coronavirus" searched produced 67 sites for analysis. However, only $24.2 \%$ of the questions of the questionnaire were answered fully, while $62.5 \%$ did not answer them at all and $13.3 \%$ simply cited them without giving details. Notwithstanding this, $99 \%$ of the contents were published by official entities, dental websites or articles assisted by oral health care professionals. Conclusion: although reliable, the search results presented little information that would really help a layperson understand the relationship between Coronavirus and dentistry, which demonstrates the need to create official channels to disseminate such information to the public in an appropriate manner.

Keywords: Coronavírus; Infections; Dentistry; Mouth; Pandemics.

\section{Introduction}

I n December 2019, a new coronavirus emerged in the city of Wuhan, Hubei province in China, starting an epidemic of a new respiratory disease in humans (COVID-19). ${ }^{1,2}$ The virus spread worldwide and in March 2020 the World Health Organization (WHO) officially declared SARS-CoVID-2 a pandemic. ${ }^{3,4}$ In February 2020, the first case of the disease in Brazil was reported and community transmission was confirmed on March 20, $2020 .{ }^{5}$ Since then, various social and professional changes have been imposed on individuals and their behavior, and these demand significant care and attention from everyone, especially from health professionals.

In this unparalleled situation, dental surgeons find themselves overly exposed to the risk of infection from the new coronavirus. ${ }^{6}$ This high level of exposure is due to their possible contact with saliva, blood and other fluids, as well as their proximity to the face of their patients. Dental aerosols emitted during clinical procedures can also be considered a high risk of infection. The relationship between Dentistry and COVID-19 is very important, as there are changes in biosafety protocols and restrictions to the treatments that can be given during this pandemic. Temporarily, only emergency and urgent procedures are allowed. Moreover, the general population must be clearly informed of the measures they should take in this period of social isolation in order to preserve their oral health and to minimize the forms of contagion due to the high viral load found in the oral cavity. ${ }^{7-9}$

The quest for information in this current situation has become of paramount importance in order to keep up with the constant changes in the diffusion of data related to COVID-19 and health. The internet is now more than ever a reality in this quest for up-to-date information. Approximately 4.5 billion users (about $58 \%$ of the world population) have access to the internet and there are more than 2.5 billion accesses to the Google ${ }^{\circledast}$ search platform daily. ${ }^{10}$ The amount of health information available online is enormous and many of the accesses for information is to obtain a better understanding of certain diseases and even information on diagnoses and treatments. The Google platform is considered the most accessed and is constantly used for health research. ${ }^{11}$ Unfortunately, the internet, despite being a good source for information, also presents content that is not always reliable. We are currently experiencing a "storm of information". In this scenario, a significant amount of health data is being created and/or replicated, mainly through social networks, without the necessary scientific rigor or even verification of the origins and sources of such information. Consequently, the general population often become misinformed by this unverified information. ${ }^{12}$ The present study aims to evaluate the information available to laypeople in Brazil on the Google search site regarding the dentistry-coronavirus interface. 


\section{Material and Methods}

The study applied a descriptive and observational design and all data were collected in April 2020 through a simple search on the Google ${ }^{\varpi}$ website (www.google.com.br). The methodology presented here was based on a previous study, which reported on the available information about dental caries transmission in children. ${ }^{11}$

The terms "Coronavirus and dentistry", "Oral health and Coronavirus" and "Tooth fracture and Coronavirus" were used in the data search. These expressions were chosen in order to simulate a search by a layperson. The results of the first three search pages for each term were used, giving 30 sites per term and a final total of 90 sites. Any sites referring to scientific articles, videos, images and question- $\&$-answer sites, as in the previously published study, were excluded. Sites that appeared two or more times were only included once and two other sites were excluded as they contained several different themes with no relation to each other despite presenting the two search words Coronavirus and dentistry.

A form with 10-questions pertinent to COVID-19 and dentistry was prepared and then applied to the online sites, and the answers based on the information available were collected. The form contained the following questions: 1 - Is an explanation about the corona virus and/or COVID-19 and its relationship with Dentistry presented? 2 - Does it address signs and symptoms characteristic of the virus infection? 3 - Does it address biosafety in dental care? 4 - Are preventive measures prior to dental care presented in order to reduce a viral load? 5 Are the procedures for receiving a patient and the relationship with the technical staff of the office, clinic or health unit described? 6 - Are the types of urgent and emergency care in dentistry explained? 7 - Does it address the restrictions imposed and recommendations for dental care and the ethical-legal implications? 8 - Is the language suitable for laypeople? 9 - Is there information about oral health care, emphasizing home care, in times of social isolation? 10 - Was it published by a renowned company or entity, by an oral health professional or orientated by one?

Two researchers analyzed the results obtained, and in case of doubt a third party was consulted. A qualitative approach to the contents, as well as the presence of information was applied, in which: 0 - did not present; 1 - partially presented; 2 - presented satisfactorily.

The results obtained were stored in a database in Microsoft Excel $^{\oplus}$, Office 2016, and treated by descriptive statistics through simple and relative frequency, as well as by means of an illustrative graph. On accessing the Google platform as a database, the three terms used as the selection criterion, showed the following results: "coronavirus and dentistry" (approximately 13,000,000 results); "Oral health and coronavirus" (approximately 2,050,000 results) and "tooth fracture and coronavirus" (approximately 99,300 results).

\section{Results}

Ten sites were selected from each of the first three pages for each term, making 30 sites for each term and a final total of 90 sites for evaluation. The exclusion criterion rejected videos $(n=3)$, and articles $(n=1)$; in addition any repeated sites were counted only once $(n=17)$, and sites that did not relate to the terms $(n=2)$ were excluded. Thus, of the 30 sites from the expression "Coronavirus and dentistry", 3 were excluded, leaving 27; from "Oral health and Coronavirus", 8 were excluded, leaving 22 and from "Fracture of tooth and Coronavirus" 12 were excluded, leaving 18; making a final total of 67 sites.

Evaluations were carried out on these 67 sites. The criterion to evaluate the answers used three parameters: NO where there was no answer to the question used; PARTIALLY - where the theme was only quoted but did not present indepth information; YES - where the answer presented was considered to be satisfactory by the authors.

After analysis, the following descriptions were obtained: of the 67 sites evaluated, 39\% had an explanation about the coronavirus and its relationship with dentistry; $30 \%$ did not explain this relationship, and $31 \%$ partially explained it, with little information on the topic. One of the frequent descriptions used was the definition of the disease and in particular its form of contagion, showing an intimate relationship with face and mouth, thus demonstrating the importance of its link with dentistry.

The signs and symptoms related to the disease are predominant factors for the diagnosis; however, only $28 \%$ of the sites addressed the signs and symptoms of the virus infection; $64 \%$ did not address the signs and symptoms at all, and $8 \%$ partially addressed this point with incomplete information.

In terms of biosafety in dental environments, only $27 \%$ presented information, $25 \%$ did not address the subject and $48 \%$ described it with incomplete information.

Dentistry organizations recommend a mouthwash with hydrogen peroxide solution prior to the dental appointment as a way to reduce the oral viral load. However, the use of a mouthwash was not addressed by $90 \%$ of the sites; $9 \%$ recommended its use and $1 \%$ explained the proposal only partially.

Dental care starts on arrival at the front desk through until the end of the appointment. Inside the office personal protective equipment (PPE) should be used to prevent transmission of the virus. This relationship between the waiting room and the office was not mentioned in $82 \%$ of the websites, $3 \%$ mentioned it and $15 \%$ gave this type of information only partially.

As the workday has been reduced following the recommendations of the dental organizations, dental surgeons are only attending urgencies and emergencies. Only 
$24 \%$ of the sites described these urgency and emergency restrictions; $72 \%$ did not address or explain this issue and $4 \%$ only partially addressed it.

The proposed restrictions and recommendations for dental care are of great importance to prevent the transmission of this virus; however, only $18 \%$ addressed the topic, $61 \%$ did not address it at all and $21 \%$ partially addressed it.

The language in $93 \%$ of the sites is clear to a lay reader, about $1 \%$ was very technical and not suitable for laypeople and the information in $6 \%$ presented some technical terms that might make it difficult for a layperson to understand.

Oral health care at home is fundamental in times of isolation to avoid future problems and reduce any possible urgencies and emergencies. Here, $46 \%$ of the sites addressed and reinforced such care in these times of isolation, while $54 \%$ did not mention the topic.

Most of the information was published in specialized sites or by a renowned entity in dentistry (99\%) and only $1 \%$ by a non-specialist (Figure 1 ).

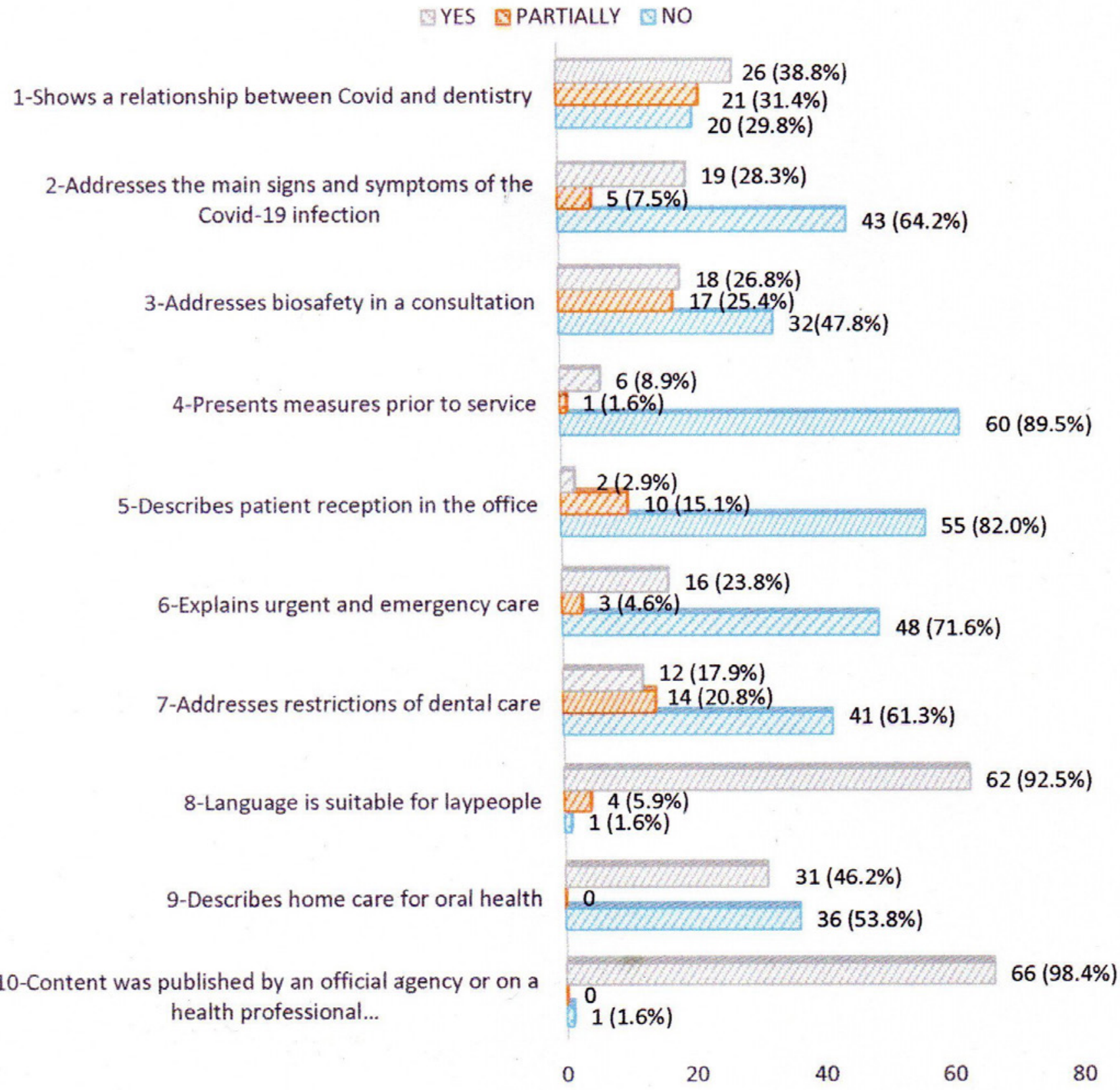

Figure 1. Questions related to Coronavirus and dentistry with the results found from the websites consulted. 


\section{Discussion}

As the coronavirus pandemic advances, the large amount of information available on Google ${ }^{\circledast}$ shows how important it is as a research tool for up-to-date sources of information. ${ }^{13}$

The health area is at risk during this pandemic, and the dental area in particular has been badly affected because dental care has been restricted to emergency and urgent services only. At these appointments, dental surgeons are exposed to the coronavirus during their work, as the virus can be transmitted from person to person, through aerosols generated by the rotation of instruments during clinical practice or in direct contact with infected saliva of a patient. For this reason, biosecurity inside and outside the office must be redoubled, and consequently the information must be disseminated so that in cases of emergency the patient with this information would go to a dental office having followed the recommendations for protection. ${ }^{6}$

During the dental procedures, the professional must be wearing a cap, an N95 mask, a face shield, goggles and gloves in addition to complying with the correct hand hygiene with soap and water. The contact surfaces around the service must also be disinfected with ethanol-based solutions (61-71\%). ${ }^{14}$

The present study sought to represent and analyze a search by the lay population, and their interests in the new virus and its relationship with dentistry. The results showed that the contents of the vast majority of websites (99\%) were published by renowned bodies, private websites of dentists or sources advised by professionals in the field. This demonstrated that the information was generally reliable. However, after analyzing the responses, the researchers realized that from the vast majority of questions asked in order to evaluate the sites, the number of responses marked as YES (in which the content was approached satisfactorily) were lower than the sum of NO and PARTIALLY responses (where the content is not addressed and only mentioned, respectively). This demonstrates that although the results of this importand subject were reliable, they were not addressed properly and in general were not very satisfactory.

This latter analysis did not consider questions 8 (Is the language comprehensible to laypeople?) and 10 (Was it published by a renowned agency, website of oral health professionals or advised by it?). They were removed from the calculation because the questions were not considered for the search itself but were evaluating the site. Thus, 24.2\% YES answers were obtained, $62.5 \% \mathrm{NO}$ and $13.3 \%$ PARTIALLY (where the content was only mentioned, without further clarification). This shows that the PARTIALLY (only citations) and NO (content not covered) together added up to $75.8 \%$.

Despite this, the results were considered convincing in terms of explaining the relationship between coronavirus and dentistry (39\%) and in the question of home care (46\%). Therefore, in some ways the results show that this research can be considered as a positive support to laypersons, especially in the explanations of home care and how to take care of oral health in times of social isolation. Some YES sites reinforced tooth and tongue brushing, flossing and mouthwashes, as well as guidelines on toothbrush storage. ${ }^{15,16}$ Furthermore, emphasis was given to these precautions as that can help in the non-propagation of the virus, since it has a high retention capacity in the oral mucosa and on the tongue.

In the dental office, the procedures to reduce the patient's viral load, such as mouthwash with hydrogen peroxide prior to care, were only explained by $8.9 \%$ of the sites. However, this is a procedure that should be up to the surgeon-dentist at the time of the consultation. Mouthwashes are recommended as the new coronavirus has been demonstrated to be vulnerable to oxidation. ${ }^{6}$

In view of the lack of knowledge concerning the potential of the virus infection in saliva, and the abundant formation of aerosols in dental treatments, a study reported that SARSCoV-2 has a viable titration of, on average, 1.1 hours in aerosols and half-life on plastic and stainless steel of $6.8 \mathrm{~h}$ and $5.6 \mathrm{~h}$ respectively. At this time, the dental regulatory bodies are suggesting that only urgent and emergency treatments should be performed. ${ }^{17}$ These urgent and emergency situations are classified by the Federal Council of Dentistry (Conselho Federal de Odontologia, CFO) and American Dental Association (ADA) as: situations that increase the risk of death to the patient (uncontrolled bleeding, cellulite and abscesses) and those that determine priority for care but do not represent a risk of death (toothache, extensive carious lesions and restorations). ${ }^{18}$ However, only $23 \%$ of the sites clearly defined what these types of assistance were, which shows that there should be more information related to these guidelines. Likewise, care with biosafety in the office was only discussed by $26.8 \%$ of the sites, which demonstrates that it is an important topic; however, it tended to appear only in more technical discussions.

Coronavirus is a simple, positive-stranded ribonucleic acid (RNA) virus that infects alveolar cells and multiplies rapidly, causing rapid and massive production of a variety of cytokines, including interferons (IFNs), interleukins (ILs), chemokines, colony-stimulating factors (CSFs), and tumor necrosis factors (TNFs), in body fluids. The main symptoms are fever, dry cough, fatigue, sputum and dyspnoea. The information of great importance such as signs and symptoms are not addressed in most of the sites; only $28.3 \%$ of the sites informed the lay person correctly. ${ }^{19}$ If the patient presents the above signs and symptoms, he must report this before any dental consultation so that the consultation can be postponed and the patient advised to seek medical assistance. ${ }^{8}$

Among the limitations of this study, there is the fact that this theme is very recent and the knowledge of the disease 
is limited and, furthermore, information is constantly being updated. Another limitation is the fact that if the research was carried out at another time, the pages found would probably be different, bringing changes in the results. However, it does not remove the value of this study in the sense that it points out that information available to the public must be monitored and under constant surveillance by competent parties because there is a great risk that lay people rely overly on their own perceptions when making judgments about scientific claims. ${ }^{20}$

\section{Conclusion}

A search for information on the relationship between coronavirus and dentistry on the Google ${ }^{\varpi}$ search platform showed that the majority of the sources were reliable. However, most of the sites did not present complete information about the aspects sought in this study. This demonstrates that, despite the great penetrating power of the internet, official channels for the dissemination of information must be more aware of the need to help the public and in a more appropriate manner.

\section{References}

1. World Health Organization (WHO). 2020. Coronavirus disease (COVID-2019 situation reports. [Accessed on May 29, 2020]. Available from: https://www.who. int/emergencies/diseases/novel-coronavirus-2019/situation-reports.

2. Li Q, Guan X, Wu P, et al. Early transmission dynamics in Wuhan, China, of novel coronavirus-infected pneumonia. N Engl J Med. 2020;382(13):1199-1207.

3. Ather A, Patel B, Rupurel NB, Diogenes A, Hargreaves KM. Coronavirus Disease 19 (COVID-19): Implications for Clinical Dental Care. J Endod. 2020;46(5):584-95.

4. Mahase E. China coronavirus: WHO declares international emergency as death toll exceeds 200. BMJ. 2020;368:m408.

5. Ministério da Saúde. Portaria 454. 2020. [Accessed on May 29, 2020]. Available from: https://www.saude.gov.br/boletins-epidemiologicos.

6. Peng X, Xu X, Li Y, et al. Transmission routes of $2019 \mathrm{n}-\mathrm{CoV}$ and controls in dental practice. Int J Oral Sci. 2020;12(1):9.

7. Kamate SK, Sharma S, Thakar S, et al. Assessing Knowledge, Attitudes and Practices of dental practicioners regarding the COVID-19 pandemic: A multinational study. Dent Med Probl. 2020;57(1):11-7.

8. Tuñas ITC, da Silva ET, Santiago SBS, Maia KD, Silva-Júnior GO. Doença pelo Coronavírus 2019 (COVID-19): Uma abordagem preventiva para Odontologia. Rev Bras Odontol. 2020;77:e1766.

9. Centers for Disease Control and Prevention. 2020. Recommendations for putting on and removing personal protective equipment for treating COVID-19 patients. [Accessed on May 29, 2020].Available from: www.cdc.gov/hai/pdfs/ppe/ ppe-sequence.pdf.

10. Internet Live Stats. Internet Users in the world. [Accessed on May 29, 2020]. Avaibable from: http://www.internetlivestats.com.

11. Cruz RL, D’Hyppolito IM, Barja-Fidalgo F, Oliveira HO. "Cárie é transmissível?” Tipo de informação sobre transmissão da cárie em crianças encontrada através da ferramenta de busca Google ${ }^{\circledR}$. Rev Bras Odontol. 2017;74(1):68-71.

12. Effron DA, Raj M. Misinformation and Morality: Encountering Fake-News Headlines Makes Them Seem Less Unethical to Publish and Share. Psychol Sci. 2020;31(1):75-87.

13. Kluger N, Scrivener Y. The use of Google trends for acral symptoms during COVID-19 outbreak in France. J Eur Acad Dermatol Venereol. 2020. In press.

14. Baseer MA, Ansari SH, AlShamrani SS, et al. Awareness of droplet and airborne isolation precautions among dental health professionals during the outbreak of corona virus infection in Riyadh city, Saudi Arabia. J Clin Exp Dent. 2016;8(4):e379-87.

15. Busato CD, Cavazzola AS, Ortega AOL, Guaré RO, Neto AS. Utilização do hipoclorito de sódio na descontaminação de escovas dentais: estudo in vitro [The use of sodium hypochlorite for toothbrushes decontamination: in vitro study]. Rev Odontol UNESP. 2015;44(6):335-9.

16. Xu H, Zhong L, Deng J, et al. High expression of ACE2 receptor of 2019-nCoV on the epithelial cells of oral mucosa. Int J Oral Sci. 2020;12(1):8.

17. van Doremalen N, Bushmaker T, Morris DH, et al. Aerosol and Surface Stability of SARS-CoV-2 as Compared with SARS-CoV-1. N Engl J Med. 2020;382(16):1564-7.

18. ADA. Interim Guidance for Management of Emergency and Urgent Dental Care. 2020. [Accessed on May 29, 2020]. Available from: https:/www.ada.org/ interimguidance.

19. Yang CL, Qiu X, Zeng YK, et al. Coronavirus disease 2019: a clinical review. Eur Rev Med Pharmacol Sci. 2020;24(8):4585-96.

20. Scharrer L, Rupieper Y, Stadtler M, Bromme R. When Science Becomes Too Easy: Science Popularization Inclines Laypeople to Underrate Their Dependence on Experts. Public Underst Sci 2017;26(8):1003-18.

\section{Mini Curriculum and Author's Contribution}

1. Natan Mecler - DDS; PhD student. Contribution: Literature review, preparation, writing, and review of the manuscript. ORCID: 0000-0002-5065-530X

2. Thiago Senna - DDS; PhD student. Contribution: Literature review, preparation, writing, and review of the manuscript. ORCID: 0000-0003-3500-6755

3. Beatriz Tholt - DDS; PhD. Contribution: Writing, and review of the manuscript. ORCID: 0000-0001-7783-3586

4. Josué Lima-Junior - DDS; PhD. Contribution: Writing, and review of the manuscript. ORCID: 0000-0002-5848-404X

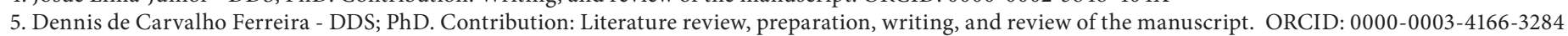

Submitted: 06/22/2020 / Accepted for publication: 06/29/2020

Corresponding author:

Natan Mecler

natanmecler@gmail.com 